\title{
Interferon-Induced Vitiligo in a Patient with Chronic Viral Hepatitis C Infection

\begin{tabular}{|l|l|l|}
\hline H. & & Simsek \\
\hline C. & & Savas \\
\hline H. & & Akkiz \\
\hline H. & & Telatar \\
\hline
\end{tabular}

Hacettepe University Medical School, Department of Internal Medicine, Section of Gastroenterology, Ankara, Turkey

\section{Key Words}

Interferons

Chronic Hepatitis C

Vitiligo

\section{Abstract}

Vitiligo is an autoimmune disease characterized by depigmentation of the skin due to destruction of melanocytes. Interferons have been used for the treatment of chronic hepatitis $C$ and some malignancies. We report interferon alpha-2a-induced vitiligo in a male patient with chronic active hepatitis C. All skin lesions disappeared completely without requiring therapy after discontinuation of interferon. This case suggests that vitiligo may be developed during interferon therapy as a side effect.

Halis Simsek, MD, Hacettepe University Medical School, Section of Gastroenterology, Ankara (Turkey)

\section{Introduction}

Vitiligo is an acquired dermatologic disorder characterized by local, dispersed or diffuse depigmented patches on the skin caused by disappearance of functional melanocytes [1]. The interferons (IFNs) are natural proteins with antiviral, antitumoral and immu-nomodulating functions. They have been successfully used for the treatment of chronic hepatitis C [2]. Several autoimmune side effects of IFN treatment including thyroid dysfunction and psoriasis are reported $[3,4]$. Interferon-induced vitiligo was previously .reported in IFN-containing combination chemotherapy regimes for melanoma [5]. Recently, a case of alopecia followed by development of canities and vitiligo has been reported 3 months after discontinuing alpha-INF therapy [6]. We report a case of IFN induced vitiligo during therapy of chronic hepatitis C. Case Report

A 39-year-old asymptomatic male with a previous history of blood transfusions was referred to our hospital because of elevated serum transaminases levels. He did not have any personal or family history of autoimmune diseases. Physical examination was unremarkable except for a hepatomegaly of $2 \mathrm{~cm}$. Laboratory analysis of blood showed a serum alanine aminotransferase level of

$219 \mathrm{IU} / \mathrm{ml}$, aspartate aminotransferase of $64 \mathrm{IU} / \mathrm{ml}$. Hepatic markers were negative with the exception of antihepatitis $C$ virus antibody positivity. A high level of liver enzymes continued for a 6-month follow-up and a percutaneous liver biopsy confirmed the diagnosis of chronic hepatitis C infection. Recombinant IFN alpha-2a (Roferon, Roche) treatment was started at a 
dose of 3 MIU, s.c. 3 times a week. One month later, hypo- and depigmented macules developed in the anterior area of the patient's neck. A diagnosis of vitiligo was made and local corticosteroid ointment was applied. Partial improvement was observed on the skin lesions with this local treatment during IFN therapy. But all skin lesions healed completely without requiring any corticosteroid therapy after discontinuation of IFN and the patient was followed up for another 10 months free of vitiligo.

Discussion

Vitiligo is an acquired, idiopathic hypo-melanotic disease characterized by circumscribed depigmented macules. Despite several investigations the cause of vitiligo still remains unknown. Three theories on the pathogenesis of vitiligo exist: (1) the immune hypothesis, (2) the neural hypothesis, and (3) the self-destruction hypothesis. Recently, it was suggested that vitiligo is a primary failure of keratinocytes [7]. Vitiligo is generally accepted as an autoimmune disease on the basis of the following evidence: presence of autoantibodies against melanocytes [8], association of the disease with HLA antigens [9], association of the disease with other autoimmune conditions such as thyroid diseases, adrenal insufficiency, diabetes mellitus and autoimmune chronic active hepatitis. Autoimmune destruction of melanocytes may be caused by both cell-mediated and humoral immunity [10]. Vitiligo-like lesions also have been reported in 4 patients with melanoma treated with interleukin 2 [11].

The IFNs have numerous effects on the cells of the immune system by altering cell growth and differentiation. In general, the effects of INFs are antiproliferative and induce cellular differentiation. The mechanism of action of IFN in the development of vitiligo is not clear. It may induce antimelanocyte autoantibodies which destroy normal melanocytes, or it may act an inducing factor for vitiligo by activation of cytotoxic T cells. But the other drugs which were used in combination with IFN may have had a role in the development of vitiligo in previous cases [5]. A patient with chronic hepatitis $\mathrm{C}$ infection developed vitiligo 3 months after discontinuing alpha-INF therapy, and vitiligo was still persistent 6 months after discontinuing therapy [6]. But in our case vitiligo had disappeared after INF therapy. We conclude that autoimmune side effects should be closely monitored during IFN therapy of chronic active hepatitis $\mathrm{C}$.

\section{KARGER}

E-Mail karger@karger.ch Fax+ 41613061234 http://www.karger.ch.

(C) 1996 S.KargerAG, Basel

1 ü 18-8665/96/1931-0065\$10.00/0

\section{References}

Ortonne JP, Bose SK: Vitiligo: Where do we stand? Pigment Cell Res 1993;6:61-72.

Simsek H: Interferon-alpha treatment of he-modialysis patients with chronic viral hepatitis $\mathrm{C}$ and its impact on kidney transplantation. Nephrol Dial Transplant, in press.

Primo J, Hinojosu J, Moles JR, Fernandez J, Martinez J, Miralles A, Otte A: Development of thyroid dysfunction after alpha-interferon treatment of chronic hepatitis C. Am J Gastro-enterol 1993;88:1976-1977.

García-Lora E, Tercedor J, Massare E, Lopez-Nevot MA, Skiljo M, Garcia-Mellado V: Interferon-induced psoriasis in a patient with chronic hepatitis C. Dermatology 1993; 187: 280.

Harris J, Bines S, Das Gupta T: Therapy of disseminated metastatic melanoma with recombinant alpha $2 \mathrm{~b}$-interferon and piroxicam: Clinical results with a report of an unusual 
response-associated feature (vitiligo), and unusual toxicity (diffuse pulmonary interstitial fibrosis). Med Pediatr Oncol 1994;22:103-106. Bernstein D, Reddy KR, Jeffers L, Schiff E: Canities and vitiligo complicating interferon therapy for hepatitis C. Am J Gastroenterol 1995;90:1176-1177.

Schallreuter KU, Lemke R, Brandt O, Schwartz R, Westhoven M, Montz R, Berger J: Vitiligo and other diseases: Coexistence or true association? Dermatology 1994;188:269-275.

Naughton GK, Eisinger M, Bystryn JC: Antibodies to normal human melanocytes in vitiligo. J Exp Med 1983;158:246-251.

Lorini R, Orecchia G, Martinetti M, Dugoujon JM, Cuccia M: Autoimmunity in vitiligo; relationship with HLA, Gin and Km polymorphisms. Autoimmunity 1992;1:255-260.

Abdel-Naser MB, Kruger-Krasagakes S, Kra-sagakis K, Gollnick H, Orfanos CE: Further evidence for involvement of both cell mediated and humoral immunity in generalized vitiligo. Pigment Cell Res 1994;7:1-8.

Wolkenstein P, Chosidow O, Guillaume JC, WechslerJ, Avil MF, RevuzJ: Vitiligo-like lesions in melanoma treated with interleukin-2: 4 cases. Ann Dermatol Vénéréol 1992; 119: 907-909. Dermatology 1996;193:66-67

M.A. Muñoz A.M. Pérez-Bernai EM. Camacho

Departamento de Dermatología M.Q. y Venereología, Hospital Universitario Virgen Macarena, Sevilla, España

Key Words

Lichenoid eruption Blaschko lines Drug reactions Nicergoline

Lichenoid Drug Eruption Following the Blaschko Lines

Abstract

Eruptions similar to those of lichen planus (LP) are associated with systemic diseases or have been induced by many drugs. Linear lesions as a Koebner effect are frequently found in LP but isolated long, narrow, linear lesions, which may extend the whole length of the limb, are rare though rather more common in childhood. Some cases of zonal or zosteriform LP have been described in the literature. We describe a case of LP with a linear distribution following the Blaschko embryologic lines induced by nicergoline in a 65 -year-old woman with a 6-month history of a pruritic eruption of erythematoviolaceous papules on the left breast, trunk and upper limb, with histological features of LP. It would be the first case of linear LP associated with drugs.

Linear and zosteriform variants of lichen planus (LP) are rare forms of LP. To our knowledge these forms of LP have not been associated with drugs. We describe a case of LP with a linear distribution following the Blaschko embryologic lines induced by nicergoline.

Case Report

We observed a 65-year-old woman with a history of hypertension treated with nicergoline, an $\alpha$ adrenergic blocking agent, for

6 months. She presented a pruritic eruption with a linear distribution 4 months after beginning this treatment. Physical examination revealed an erythematoviolaceous eruption consisting of flat-topped shiny papules along the Blaschko lines affecting the left breast, hemithorax, axillae with an ' $S$ ' shape and a longitudinal location on the ventral side of the left arm (fig. 1). Routine laboratory examination including blood count and hepatic parameters as well as spinal cervical 
and dorsal column X-rays were normal. The cutaneous biopsy showed hyperkeratosis with prominent focal hypergranulosis, Civatte bodies

and hydropic degeneration of the basal epidermal layer with Max-Joseph spaces. A lichenoid lymphocytic infiltrate with numerous eosinophils in superficial and mid-dermis was present. Treatment with nicergoline was stopped and 2 months later only a residual lesion on the axillae remained which was infiltrated with betametasone $(3 \mathrm{mg} / \mathrm{ml})$ and 1 month later had completely disappeared.

Lichenoid drug eruption (LDE) may be clinically identical to idiopathic LP and a detailed clinical history is important in order to make the diagnosis [1], Numerous drugs can be inducers of LDE [2] and $\alpha$-adrenergic

\section{KAKGER}

E-Mail kargerф $7 / 8$ arger.ch Fax+ 41613061234 http://www.karger.ch

(C) 1996 S.KargerAG, Basel 1018-8665/96/1931-0066\$10.00/0

Miguel A. Muñoz Departamento de Dermatología Hospital Virgen Macarena Avda. Dr. Fedriani s/n E-41075 Sevilla (Spain)

Received: October 19. 1995 Accepted: January 26, 1996 